\title{
Nurse's perioperative care errors and related factors in the operating room
}

\author{
Jaber Zabihirad', Soheila Mojdeh², Mohsen Shahriari ${ }^{3}$
}

\begin{abstract}
Introduction: Surgical cares are one of the most complex and costly health care services and optimizing them should be prioritized. Medical error as an adverse event can be considered as a threat to the safety of the patients. The revelation of errors is recognized as the basis for maintaining and improving the safety of patients; consequently, the present study aimed to investigate pre-, intra- and postoperative care errors in the operating rooms and their related factors.

Method: This descriptive-analytic study was conducted in the operating rooms of selected hospitals of Isfahan University of Medical Sciences. The research instrument was a researcher-made questionnaire including demographic information, errors perioperative care and effective factors on these sorts of medical cares. Data were entered into SPSS software and analyzed by statistical tests.

Findings: The mean error in the perioperative care was $25.33 \%$, the highest error rate was related to preoperative care $(31 \%)$ and then the error in postoperative care $(25.24 \%)$ and the lowest level of error rate was seen in line with intraoperative care (20.75\%); the results showed that the most effective factor in the occurrence of care errors in the operating room were environmental and structural factors (80.25\%), then individual factors (75.27\%) and management factors (61.75\%).

Conclusion: Regarding the lesser intraoperative cares error, it can be concluded that nurses are more focused on surgical procedures and surgical principles in line with the operation and are more likely to play a role of the assistant surgeon in the operating room and pay less attention to nursing care before and after the operation.
\end{abstract}

Keywords: medical error, operating room, perioperative care

\section{INTRODUCTION}

Medical science is based on the principle "First, do no harm." Despite the development in technology and healthcare, medical errors can lead to damage to patients (1-3). Patient safety is defined as "absence of adverse events." (4) Ensuring patient safety before injury is a concern of all health care providers, so patient safety is a matter that is inherently related to professional identity (5). Safe surgery is defined as protecting patients from potential medical errors or minimizing mistakes during pre, intra, and post-operative stages (6). Surgical care is one of the most complex and costly health care services and its optimization should be prioritized (7).

Medical error is defined as an adverse event or failure to achieve desirable outcomes (8). In order to enhance patient safety, prevention of health-related harms is a critical and comprehensive component of health care providers. Although it is likely that these harms can be preventable, but in some cases, prevention of certain injuries may be inevitable (9). Medical errors include a wide range of incidents, including drug errors, errors in patient identification, and errors or delays in diagnosis. In addition to the mistakes that may be made by any medical practitioner, mistakes made by the surgeons include wrong site surgery and wrong procedure. These errors can be significant and lead to significant

\footnotetext{
1 MSc student in Operating room, Student Research Committee, Faculty of Nursing and Midwifery, Isfahan University of Medical Sciences, Isfahan, Iran

2 MSc in Nursing, Ulcer Repair Research Center, Department of Operating Room, Faculty of Nursing and Midwifery, Isfahan University of Medical Sciences, Isfahan, Iran

3 Associate Professor, Nursing and Midwifery Care Research Center, Adult Health Nursing Department, Faculty of Nursing and Midwifery, Isfahan University of Medical Sciences Isfahan, Iran
}

Correspondence: Soheila Mojdeh

MSc in Nursing, Ulcer Repair Research Center, Department of Operating Room, Faculty of Nursing and Midwifery, Isfahan University of Medical Sciences, Isfahan, Iran

E-mail:mojdeh@mail.nm.mui.ac.ir

Received: 28 Apr 2018, Accepted: 29 May 2018

(C) 2019 by the authors; licensee Modestum Ltd., UK. This article is an open access article distributed under the terms and conditions of the Creative Commons Attribution License (http://creativecommons.org/licenses/by/4.0/). 
consequences for patient, surgeon and the hospital (10). Surgical errors are often defined in the field of medical errors; therefore, there is little information on how to define perioperative care error in surgery (11).

Various studies have shown that 53 to 70 percent of surgical errors occur in the operating room before or after surgery. So paying attention to all stages of the surgery, from patient admission to discharge, led to significant progress in patient safety (12-15). Therefore, errors detection has been considered as the basis for maintaining and improving the safety of the patient (16). In addition, categorization of these errors and efforts to control and reduce them in operating room and identifying their associated factors, can protecting the patient's safety, prevent possible damages to patient, reduce the side effects, shorten the patient's hospital stay, reduce financial costs, and prevent similar errors in the future and can also be a valuable source of information (17).

Since the occurrence of an error in the operating room with regard to the special conditions of this part of hospital is very important and there are few studies about perioperative care errors and their related factors, this study aimed to determine perioperative care errors and related factors in the operating rooms of Isfahan University of Medical Sciences in 2017.

\section{METHOD}

This descriptive-analytic study investigated the perioperative care errors in surgical operations and the related factors affecting them in operating rooms of selected hospitals of Isfahan University of Medical Sciences in 2017. By using the related formula, the sample size was determined as 202 technologists and operating room nurses, and by taking into account a loss of 10, 222 samples were selected as the statistical population of this study.

\section{Determining the Sample Size}

$$
n=\frac{Z_{1-\frac{\alpha}{2}} P(1-P)}{d^{2}}
$$

The inclusion criteria of this study included having at least an associate degree in operation room or nursing, as well as a work experience of at least 6 consecutive months in the operation room shifts, and in case of defect in completing the questionnaire they were excluded from the study, and 10 people were excluded from the study.

The data collection tool was a researcher-made questionnaire that was compiled by using valid texts. This questionnaire consisted three parts: the first was demographic information, the second part related to the tasks of the operating room technologists with regard to the operation procedure, which were assessed by means of five-choice questions, with a Likert scale, (always " 0 ", often " 1 ", sometimes " 2 ", rarely " 3 ", never " 4 "), and the third part consists of three domains; environmental and structural factors, individual factors and management factors, was related to the factors affecting the error with Likert scale, (I totally agree with " 4 ", I agree " 3 ", I have no idea " 2 ", I oppose "1", totally disagree " 0 "), The content validity of the questionnaire was obtained by using the views of the 10 faculty members of the operating room group and making the necessary corrections and approving them. The reliability of the questionnaire was completed so that the questionnaire was completed by $10 \%$ of the sample size (20 people), then the Cronbach's alpha score was 0.89 . First, the mean error score was obtained in each of the domains pre-, intra- and post-operation stages, and then the mean scores were converted to percentages and classified into three categories of less error ( $0>$ $33)$, moderate error (66-33), and high error (>66). Also, the score of each of the factors associated with the operating room errors was obtained and in order to determine the average score, each of these factors was converted to zero to 100 and classified into three groups of factors with low $(-0>33)$, moderate (33-66) and high (>66) care errors in the operating room.

The researcher entered the operating room after receiving approvals from the Ethics Committee of Isfahan University of Medical Sciences (396707) and offered to the hospital authorities. After getting permission of the operating room officer at the beginning of the each working shift. Then the research objectives and the manner of completing the questionnaires were explained to the research samples. Informed consent was obtained from personnel and the participants were assured that the questionnaires would be anonymous and the received information would be confidential. Then, the questionnaires were distributed among the research samples and collected after completion at the end of the shift. Data were collected by SPSS software version 24 and analyzed by using descriptive statistics and Pearson correlation test. 
Table 1: Demographic findings

\begin{tabular}{|c|c|c|c|}
\hline & & Frequency & Frequency percentage \\
\hline \multirow[t]{4}{*}{ Overtime } & No overtime & 68 & 32.1 \\
\hline & Less than 50 hours & 88 & 41.5 \\
\hline & 50 to 100 hours & 28 & 13.25 \\
\hline & More than 100 hours & 28 & 13.25 \\
\hline \multirow[t]{4}{*}{ Shift type } & Circulating & 142 & 67 \\
\hline & Morning & 10 & 4.7 \\
\hline & Morning / evening & 59 & 27.85 \\
\hline & Night & 1 & 0.45 \\
\hline \multirow[t]{2}{*}{ Employment in several hospitals } & Yes & 75 & 35.4 \\
\hline & No & 137 & 64.6 \\
\hline
\end{tabular}

Table 2: Average error score and frequency of care errors in surgical procedures

\begin{tabular}{lll}
\hline Care phase & Frequency of error & Average error score * \\
\hline Error in preoperative cares & 31.00 & 1.24 \\
\hline Error in intraoperative cares & 20.75 & 0.83 \\
\hline Error in postoperative cares & 24.25 & 0.97 \\
\hline
\end{tabular}

Table 3: Mean score and frequency percentage of factors affecting the occurrence of errors in perioperative cares

\begin{tabular}{|c|c|c|c|}
\hline & Statistics & Frequency percentage & Average score * \\
\hline Environmental and structural factors & & 80.25 & 3.21 \\
\hline Individual factors & & 78.25 & 3.13 \\
\hline Management factors & & 61.75 & 2.47 \\
\hline
\end{tabular}

Table 4: Correlation of perioperative cares errors with different factors

\begin{tabular}{|c|c|c|c|}
\hline & Statistics & Correlation Coefficient & $P$ value \\
\hline $\begin{array}{l}\text { Factors } \\
\text { Environmental and structural factors }\end{array}$ & & 0.175 & 0.011 \\
\hline Individual factors & & 0.196 & 0.004 \\
\hline Management factors & & 0.241 & 0.0001 \\
\hline
\end{tabular}

\section{RESEARCH FINDINGS}

212 completed questionnaires were analyzed (response rate was95.5\%). The results of this study showed that $68.9 \%$ of the samples were women, $32.5 \%$ were single, $66.5 \%$ were married and one percent of the participants have lost their spouses. Also, $25 \%$ had associate degrees, $73.1 \%$ had a bachelor's degree, and only $1.9 \%$ had master's degree or higher. $32.5 \%$ have a work experience of fewer than 5 years, 25.5\% between 5 to 10 years, $17.5 \%$ between 10 and 15 years, $12.5 \%$ between 15 and 20 years, and $8 \%$ over 25 years of work experience. Other demographic findings are presented in Table 1.

The findings of the current study showed that the error mean in perioperative care was $25.33 \%$, which indicated a low error rate $(0-33 \%)$, so that the lowest error rate in intraoperative care with a mean score of $0.83 \pm 0.38$ was equal to $20.75 \%$ and the highest error rate was in preoperative care with an average score of $1.24 \pm 0.69$ was equal to $31.07 \%$, and the mean error score in postoperative care $(0.97 \pm 0.51)$ was equal to $24.25 \%$, which indicates that the error rate is low (0-33) (Table 2).

As shown in Table 3, structural and environmental factors (80.25\%), individual factors (78/25\%), had the strongest effect $(>66 \%)$ and management factors $(61.75 \%)$ had moderate effect $(33-66 \%)$ with errors in perioperative cares.

Regarding the results, all three environmental and structural, individual and management factors have a significant relationship with the occurrence of care errors in the operating room $(P<0.05)($ Table 4$)$. 


\section{DISCUSSION}

This study was performed to investigate the care errors in operational procedures and their related factors in the operating room. The results of this study showed that the error rate in preoperative care was $31 \pm 16 \%$ and the least error rate $(11.5 \%)$ in relation to preoperative care was related to checking the operation location and patient awareness about the operation and post-operative care. The study of Cohoon showed that the incidence of near misses in the holding and admission room was 35\% and the lowest error rate was related to the wrong patient with $3.1 \%$, and then the wrong side with $4.3 \%$ (18). Gorji et al. also found that out of 187 identified errors cases in 21 surgical procedures, $32 \%$ were related to preoperative processes, and he also stated that the most dangerous identified error was the admission of the patient in the operating room (19). In addition, in the study by Somville's and the error rate in the preoperative phase was mentioned $15 \%$ (20). It seems that the lower rate of error about the wrong patient and wrong side in the surgery can be due to the fact that the location of operation is marked in the wards, also once the patient entered the operation room, s/he could be asked about the side and the type of surgery, and a safety checklist is also completed by the caretakers of the operating room. However, doing operation and operation procedure is of the most important concerns of nurses in line with an operation that may lead to underestimating patients awareness in the operating room, or depending on the specific operating conditions of the operating room, patient training opportunities would not be available.

In the present study, the degree of care error in intraoperative care was $20.77 \pm 9.64 \%$. Somerville et al. reported an error rate in the intraoperative phase as $39 \%$ (20). Stone et al. also found that in $87.1 \%$ of the surgeries, errors have occurred that the highest amount of them (27.8\%) was related to the technical error and $25.3 \%$ of errors were related to infection and aseptic observance, $18.2 \%$ error cases were related to equipment and $12.5 \%$ was related to delayed operation, and only $5.7 \%$ of the errors were related to nursing care in the operating room (21). In Chen's et al., out 130 detected errors during the operation, 40 cases were related to the equipment errors, 18 were related to documentation, 16 items were related to lack of access to devices, only 6 cases were related to sterilization and 5 cases of lack of workforce; and only one case was related to loss of samples (22) and these results are not consistent with the results of the current research. It seems that the difference in the amount of error during surgery with the present study is due to the fact that they investigate all the medical errors in the operating room, such as posing the patient and nursing care, actions such as anesthesia, the presence of anesthesiologists and surgeons, and surgical technique errors which are carried out by all surgical careers, but in this research, cases related to nursing and perioperative cares (including preparing the necessary equipment for surgery, observing individual and patient safety points, observing aseptic points during the preparation of the surgical environment), the operating principles in the operating room were checked in the operating room and only perioperative and nursing care errors were investigated.

The results of the study showed that error in postoperative care was $24.25 \pm 12.84 \%$, and Gorji's et al. study indicated that only $16 \%$ of identified errors were associated with postoperative processes (19). The difference between the results of this study and the current study could be due to the fact that they also reviewed the process of drug injection in recovery, but in this study, issues such as preparing the room for the next operation, supervising the room cleaning, delivery and evolution of electrical appliances and surgical sets which is one of the tasks of nurses in operation procedure.

The results of the study about the factors affecting the occurrence of error showed that the most important factor in the occurrence of care errors in the operating room were environmental and structural factors with a mean score of $80.25 \%$ that the suitability of physical space and access to the equipment in the operating room environment were important factors in this domain. ElBardiss's et al. study results were consistent with the results of this study and they indicated that the operating room environment and its design, such as light, temperature, bustle, and noise, are factors that affect the occurrence of an error (23). On the other hand, in this study, individual factors also have an effect on an error with an average score of $78.25 \%$ and the most important factor in this context was personnel fatigue. In Bijani's et al. study in 2013 and another study by Saki et al. in 2016 it was indicated that fatigue is one of the most important factors affecting the occurrence of errors. Also, Vidyarthi et al. stated that exposure to fatigue caused an increase in stress and, consequently, increased the likelihood of an error $(1,24-26)$. The results of Khameslou's et al. study showed that nurses considered working conditions such as crowdedness, lack of workforce and exhaustion as effective factors in the occurrence of drug errors (27).

In terms of management factors, a mean score of $61.75 \%$ was obtained, which indicates a moderate effect (33-66\%) of this factor on the error occurrence. Eslamian's et al. showed that management factors were the most important factor (84.2\%) in nurses' error (28). The shortage of human resources and performing the tasks by a team were among the most important factors in the errors of this field, which is in line with the study of Bijani et al. (24). Cramer et al. also showed 
that heavy workload and a shortage of manpower are the factors affecting the incidence of nursing errors (29). Morey et al. found that improved teamwork reduced errors from $30.9 \%$ to $4.4 \%$ in the emergency department among nurses and doctors (30). In this regard, Ugur et al. also reported failure to do teamwork as an effective factor in Errors (1), and their results are consistent with the present study.

\section{CONCLUSION}

The error rate in pre and postoperative cares was higher than intraoperative care that could be due to care provider focusing on surgical procedures and surgical principles and their greater willingness to play the role of first surgeon assistant. Given the importance and the undeniable impact of pre and post operational nursing cares on patients, managers and authorities must reduce errors in pre and post-operational cares by providing suitable programs.

\section{ACKNOWLEDGEMENTS}

The present article is based on the master's thesis of the operating room approved by the code 396707 at Isfahan University of Medical Sciences. The researchers must thank all the staff of the operating rooms and the officials of the hospitals affiliated to the Isfahan University of Medical Sciences contributed to this research. We also thank the Research Deputy of this University.

\section{REFERENCES}

1. Ugur E, Kara S, Yildirim S, Akbal E. Medical errors and patient safety in the operating room. Age. 2016;33(6.53):1950.

2. Hashemi F, Nikbakht Nasrabadi A, Asghari F. The obstacles of reporting nursing errors in Iran: a qualitative study. Journal of medical ethics and history of medicine. 2011;4(2):53-64.

3. Weerakkody RA, Cheshire NJ, Riga C, Lear R, Hamady MS, Moorthy K, et al. Surgical technology and operatingroom safety failures: a systematic review of quantitative studies. BMJ Qual Saf. 2013;22(9):710-718. https://doi.org/10.1136/bmjqs-2012-001778 PMid:23886892

4. Hoffmann B, Rohe J. Patient safety and error management: what causes adverse events and how can they be prevented? Deutsches Arzteblatt International. 2010;107(6):92. https://doi.org/10.3238/arztebl.2010.0092

5. Chiozza ML, Ponzetti C. FMEA: a model for reducing medical errors. Clinica Chimica Acta. 2009;404(1):75-8. https://doi.org/10.1016/j.cca.2009.03.015 PMid:19298799

6. Candas B, Gürsoy A. Patient safety in operating room: Thoughts of surgery team members on implementing the Safe Surgery Checklist (An example from Turkey). Perioperative Care and Operating Room Management. 2016;5:1-6. https://doi.org/10.1016/j.pcorm.2016.08.001

7. Barajas-Nava L, Solà I, Delgado-Noguera M, Gich I, Villagran CO, Bonfill X, et al. Quality assessment of clinical practice guidelines in perioperative care: a systematic appraisal. Qual Saf Health Care. 2010;19(6):e50-e.

8. Makary MA, Daniel M. Medical error-the third leading cause of death in the US. BMJ: British Medical Journal (Online). 2016;353.

9. Nabhan M, Elraiyah T, Brown DR, Dilling J, LeBlanc A, Montori VM, et al. What is preventable harm in healthcare? A systematic review of definitions. BMC health services research. 2012;12(1):128. https://doi.org/10.1186/14726963-12-128 PMid:22630817 PMCid:PMC3405467

10. Shanafelt TD, Balch CM, Bechamps G, Russell T, Dyrbye $L$, Satele $D$, et al. Burnout and medical errors among American surgeons. Annals of surgery. 2010;251(6):995-1000. https://doi.org/10.1097/SLA.0b013e3181bfdab3 PMid:19934755

11. Ehsani SR, Cheraghi MA, Nejati A, Salari A, Esmaeilpoor AH, Nejad EM. Medication errors of nurses in the emergency department. Journal of medical ethics and history of medicine. 2013;6.

12. de Vries EN, Prins HA, Crolla RM, den Outer AJ, van Andel G, van Helden SH, et al. Effect of a comprehensive surgical safety system on patient outcomes. New England Journal of Medicine. 2010;363(20):1928-37. https://doi.org/10.1056/NEJMsa0911535 PMid:21067384

13. Griffen FD, Stephens LS, Alexander JB, Bailey HR, Maizel SE, Sutton BH, et al. The American College of Surgeons' closed claims study: new insights for improving care. Journal of the American College of Surgeons. 2007;204(4):561-9. https://doi.org/10.1016/j.jamcollsurg.2007.01.013 PMid:17382214 
14. Greenberg CC, Regenbogen SE, Studdert DM, Lipsitz SR, Rogers SO, Zinner MJ, et al. Patterns of communication breakdowns resulting in injury to surgical patients. Journal of the American College of Surgeons. 2007;204(4):533-40. https://doi.org/10.1016/j.jamcollsurg.2007.01.010 PMid:17382211

15. de Vries EN, Hollmann MW, Smorenburg SM, Gouma DJ, Boermeester MA. Development and validation of the SURgical PAtient Safety System (SURPASS) checklist. BMJ quality \& safety. 2009;18(2):121-.6

16. Movahednia S, Partovishayan Z, Bastanitehrani M, Moradi F. Nurse Managers' perspectives about Reasons for not reporting medical errors in Firoozgar Hospital: 2012. Razi Journal of Medical Sciences. 2014;21(125)

17. Chard R. How perioperative nurses define, attribute causes of, and react to intraoperative nursing errors. AORN journal. 2010;91(1):132-45. https://doi.org/10.1016/j.aorn.2009.06.028 PMid:20102810

18. Cohoon B. Causes of near misses: perceptions of perioperative nurses. AORN journal. 2011;93(5):551-65. https://doi.org/10.1016/j.aorn.2010.02.017 PMid:21530704

19. Gorji HA, Ravaghi H, Pirouzi M, Mansourzade A. Utilizing Integrated Prospective and Retrospective Risk Analysis Method on General Processes Patient Flow in Operating Room in Seyed Alshohada Hospital in Semirom, Iran. Health Inf Manage. 2013;10(3).

20. Somville $F$, Van Sprundel $M$, Somville J. Analysis of surgical errors in malpractice claims in Belgium. Acta Chirurgica Belgica. 2010;110(1):11-8. https://doi.org/10.1080/00015458.2010.11680558 PMid:20306903

21. Stone $S$, Bernstein M. Prospective error recording in surgery: an analysis of 1108 elective neurosurgical cases. Neurosurgery. 2007;60(6):1075-82. https://doi.org/10.1227/01.NEU.0000255466.22387.15 PMid:17538382

22. Chen Q, Rosen AK, Amirfarzan H, Rochman A, Itani KM. Improving Detection of Intraoperative Medical Errors (iMEs) and Intraoperative Adverse Events (iAEs) and their Contribution to Postoperative Outcomes. The American Journal of Surgery. 2018. https://doi.org/10.1016/j.amjsurg.2018.03.005

23. ElBardissi AW, Sundt TM. Human factors and operating room safety. Surgical Clinics. 2012;92(1):21-35. https://doi.org/10.1016/j.suc.2011.11.007 PMid:22269258

24. Bizhani M, Kouhpayeh SA, Abadi R, Tavacool Z. Effective factors on the Incidence of medication errors from the nursing staff perspective in various department of Fasa Hospital. Journal of Fasa University of Medical Sciences. 2013;3(1):88-93.

25. Saki K, Khezri_Azar J, Mohebbi I. Nursing errors and its relationship with fatigue among nurses of the emergency ward. Journal of Nursing and Midwifery Urmia University of Medical Sciences. 2016;13(10):835-42.

26. Vidyarthi AR, Auerbach AD, Wachter RM, Katz PP. The impact of duty hours on resident self reports of errors. Journal of general internal medicine. 2007;22(2):205-9. https://doi.org/10.1007/s11606-006-0065-4 PMid:17356987 PMCid:PMC1824755

27. Ajri-Khameslou M, Abbaszadeh A, Borhani F, Farokhnezhad Afshar P. Contributing factors to nursing error in emergency department: A qualitative study. Hayat. 2017;23(1):17-32.

28. Eslamian J TF, Bahrami M, Mojdeh S. Assessing the nursing error rate and related factors from the view of nursing staff. Iranian Journal of Nursing and Midwifery Research. 2010;15(Suppl1):272-7. PMid:22069399 PMCid:PMC3208929

29. Cramer $\mathrm{H}$, Pohlabeln $\mathrm{H}$, Habermann $\mathrm{M}$. Factors causing or influencing nursing errors as perceived by nurses: findings of a cross-sectional study in German nursing homes and hospitals. Journal of Public Health. 2013;21(2):145-53. https://doi.org/10.1007/s10389-012-0527-6

30. Morey JC, Simon R, Jay GD, Wears RL, Salisbury M, Dukes KA, et al. Error reduction and performance improvement in the emergency department through formal teamwork training: evaluation results of the MedTeams project. Health services research. 2002;37(6):1553-81. https://doi.org/10.1111/1475-6773.01104 PMid:12546286 PMCid:PMC1464040

$\diamond \diamond \diamond \diamond \diamond \diamond \diamond$

http://www.ejgm.co.uk 